\title{
The Role of Top Management Commitment in Enterprise Architecture Development in Governmental Organizations
}

\author{
Negin Banaeianjahromi* \\ Department of Information and Service Management, School of Business, \\ Aalto University, Helsinki, Finland \\ negin.banaeianjahromi@aalto.fi
}

\begin{abstract}
Governmental organizations adopt Enterprise Architecture (EA) not only to enhance their performance and efficiency but also to move toward egovernment implementation. The article at hand investigates the EA development obstacles in governmental organizations. An interpretivist paradigm using the grounded theory methodology (GTM) was selected to carry out this study. The data were collected through semi-structured interviews with 9 governmental organizations in Iran. In total, 17 obstacles were identified. This study revealed the precedence in addressing EA development obstacles and top management commitment category was identified as a category that has the highest impact on the EA projects. It was realized that the commitment that top management level of the organizations show toward EA development projects, motivates employees to effectively engage with the projects. In addition, a committed top manager assigns adequate resources to the EA project in order to prepare the infrastructure of the company. In this study, government and politics category appeared to be a category of external obstacles that affects most of the other categories directly or indirectly. This study contributes to industry and academia by investigating the EA development obstacles.

Keywords: Enterprise Architecture, Information Systems, Obstacles, Development Challenges, Governmental Organizations, E-Government, Iran, Grounded Theory.
\end{abstract}

\section{Introduction}

Enterprise Architecture (EA) has been evolving significantly since 1987 when John Zachman introduced the concept for the first time [1]. Organizations adopt EA to manage complexities and align business and IT, promote interoperability among information systems, minimize the costs, and maximize the return on investment [2]. However, organizations still face many challenges and obstacles when adopting EA [3]-[5].

\footnotetext{
* Corresponding author
}

(C) 2018 Negin Banaeianjahromi. This is an open access article licensed under the Creative Commons Attribution License (http://creativecommons.org/licenses/by/4.0).

Reference: N. Banaeianjahromi, "The Role of Top Management Commitment in Enterprise Architecture Development in Governmental Organizations,” Complex Systems Informatics and Modeling Quarterly, CSIMQ, no. 17, pp. 95-113, 2018. Available: https://doi.org/10.7250/csimq.2018-17.05

Additional information. Author's ORCID iD: N. Banaeianjahromi - https://orcid.org/0000-0001-5218-3118. PII S225599221800101X. Received: 18 October 2018. Accepted: 27 November 2018. Available online: 31 December 2018. 
In the Information Systems (IS) literature, frameworks, methodologies, best practices, and practical recommendations to develop EA in governmental organizations have been well discussed [6]-[12]. In Iran, the majority of EA studies have focused on EA frameworks, methodologies, assessment methods, framework analyses, and best practices [13]-[19].

In Iran, EA projects (developing an EA in an organization) are usually carried out by an external EA-consultant. In 2003, Iran's government established an IT architecture committee to assist governmental organizations in EA development by conducting several EA workshops and seminars to eventually create a national enterprise architecture [20]. In a web-form based survey conducted by Institutes for Enterprise Architecture Developments, enterprise architecture activity ranking was provided to compare high ranked countries in 2004 and 2005 regarding their EA activities [21]. According to this report in 2004, Iran was ranked among the top ten countries regarding its EA activities, however in 2005 Iran's rank became to $13^{\text {th }}$. Since 2005 no specific international ranking has been carried out regarding the EA activities. However, according to the United Nations report in 2014 on world e-government ranking, in which EA activities are being considered as one of the aspects that influenced this ranking, Iran ranks $105^{\text {th }}$ in the world [22]. This significant collapse of Iran's rank compared to other countries regarding EA activities in governmental sections motivated the author to conduct this study. This study aims to identify the EA development obstacles in Iran's governmental organizations. The uniqueness of some of the identified obstacles due to the peculiar political stance of Iran is also discussed in this article.

Many studies have discussed EA challenges in governmental organizations [11], [12], [23][32]. The aim of this study is first, to increase the understanding of EA development obstacles in governmental organizations and second, to look for a core category with the highest priority when addressing EA obstacles. In contrast to most of the EA studies that approach EA development from software and system engineering perspective [33], the major focus of this study is on the socio-managerial aspect of EA development. To conduct this study, 14 interviews with EA experts from 9 large governmental organizations in Iran were analyzed. Employing Grounded Theory Methodology, 18 obstacles were identified.

In this article, after surveying the background of this study in Section 2, the research process is discussed in Section 3 and data collection and data analysis are explained. In Section 4, the findings of the study are presented and the discussion on these outcomes is provided in Section 5. Finally, the conclusion is presented in Section 6.

\section{Background}

An enterprise Architecture (EA) provides structured descriptions of organizational entities and their relationships to manage organizational complexities [1], [34]-[38]. There is no universally accepted definition of EA [39]. This article adopts a general definition of EA [40]: "an approach to manage organizational, structural, and technological complexity by providing a holistic view of the organization to achieve the organization's strategic goals".

Although EA has been growing steadily since the 1980s [1], practitioners still face many obstacles in the process of EA development. Several studies have presented challenges and critical factors during EA development in different countries, such as Finland, Sweden, Netherlands, Denmark, Germany, and the United States [11], [12], [23]-[28], which are discussed in the following.

For the sake of clarity, in this study, an EA obstacle is defined as a factor which confronts EA projects with difficulties and loss of resources that cannot be solved easily and may even lead to the project termination.

The challenges of EA development in governmental organizations from stakeholder perspective have been studied by Isomäki and Liimatainen (2008) [25]. In their study, Isomäki and Liimatainen identified three main categories of EA challenges: (1) implementation ability and governance, (2) the structure of state government, and (3) advancement of interoperability. In another study, Seppänen et al. (2009), determined three key issues in EA implementation by 
studying two governmental agencies [27]: (1) the lack of establishing proper EA governance, (2) insufficient support for the development, and (3) inadequate resources to achieve the former two. Furthermore, Saarelainen and Hotti (2011), identified four EA challenges while investigating the role of EA in the E-Government program [29]: (1) difficulties to introduce EA thinking to the whole project, (2) executive group does not understand the meaning and purpose of EA, (3) lack of shared understanding and communication, and (4) lack of understanding of the whole picture. In another study, Valtonen et al. (2011) proposed EA as a tool for improving the coherency of the local government and its alignment to IT and other resources through an action research [30]. They discussed the perceived challenges for EA in public administration and pointed out few challenges, such as (1) the cost of change in personnel, (2) challenges in adopting a common framework for common understanding, (3) lack of leaders' trust, and (4) lack of coordination and collaboration.

Chuang and Loggerenberg (2010) studied the challenges that enterprise architects faced particularly in the South African organizational context [31]. Aiming to examine the nontechnical aspects of the architecting process, they conducted eight interviews with enterprise architects working in the EA domain in different industries. They identified five challenges: (1) communication, (2) obtaining buy-in from the stakeholders, (3) ownership, (4) perceptions of the enterprise architect, and (5) organizational politics.

The article at hand will improve the body of Information systems (IS) knowledge by studying the EA development challenges in governmental organizations in Iran and provide new insight into the field by extending the list of EA development obstacles. Furthermore, this study will identify the precedence in addressing EA development obstacles using the grounded theory approach by identifying the core category.

\section{Research Process}

The objective of this study is to contribute to the field of IS by examining the EA development obstacles in governmental organizations from management level perspective. The cases of this study were selected from governmental organizations in Iran. To carry out this study, the interpretivist paradigm using the grounded theory methodology (GTM) was employed. GTM is a research methodology proposed by Glaser and Strauss to systematically derive theory from empirical data on social contexts [41]. GTM's effectiveness is in the systematic approach of data collection and analysis that grounds the theory creation based on reality [42]. The process of data collection and analysis were done iteratively by investigating each organization at a time. Strauss and Corbin's coding approach was followed to analyze the data, which includes open, axial and selective coding. Coding represents "the analytic processes through which data are fractured, conceptualized, and integrated to form theory" [43].

Adoption of GTM has benefited the study by employing 'open-minded' attitude toward the empirical data to let empirical observations and theoretical insights influence the research interest [44], [45]. The research questions were developed as the research moved forward based on the perception of the researcher from the data analysis. Memos and notes were written during the process of data collection and analysis to keep track of thoughts. The initial research questions of this study were formulated as "what are the obstacles that practitioners faced during the EA development projects in governmental organizations from management level perspective?" and "What obstacle should be addressed in priority?" Later, in the research process a third research question was identified and answered: "How does top management commitment related obstacles relate to the other categories?"

\subsection{Data Collection}

Through purposeful sampling [46] in the period from May to July 2015 data were collected from 9 organizations (Table 1). For the purpose of this study, 14 experts were interviewed, with the 
average duration of the interviews being 1 hour and 20 minutes. The interviews were conducted in the interviewees' workplaces. The interviewees were from the management level of the organizations and the organizations were considered as large with sizes from 1500 to 35,000 employees. At the time of conducting the interviews EA was implemented and adopted by the organizations, and some of these organizations were in the stage of updating their current EA.

The process of purposeful sampling was initiated by sending an email to an EA specialist mailing list that encompassed 335 members and request from members of the group to assist with the interviews. 38 replies were received and in the next step the researcher telephoned the candidates and provided them with more information about the project and asked for the candidates' backgrounds and their roles within the EA projects in their organizations. Finally, 14 experts from the management level of the organizations who were intensely involved in an EA project in governmental organizations were selected. Chief Executive Officers (CEO), Chief Information Officers (CIOs), IT managers, and heads of related departments were among roles of the interviewees. The interviews' questions were theme based including topics, such as the obstacles, missions, and goals of the EA project in different EA development stages, as well as the results and outcome of the project. Table 1 presents the information about the interviewed organizations. The researcher considered semi-structured interviews with open-ended questions to be suitable for data collection in order to ensure the quality of the interviews. The interviewer ensured that all of the pre-planned themes were covered and the interviewees reflected on the topics as well as brought their experience and perceptions to the discussion [47]. Open-ended questions were used during the interviews and the interviewees could reflect more deeply on the topic and more detailed questions were asked when required.

Table 1. Information about conducted interviews and the organizations

\begin{tabular}{|l|l|l|l|}
\hline Cases & Number of employees & Number of interviews & Interviewed roles \\
\hline A & 1500 & 1 & CIO \\
\hline $\mathbf{N}$ & 1860 & 1 & IT manager \\
\hline $\mathbf{G}$ & 10000 & 3 & $\begin{array}{l}\text { CIO } \\
\text { Head of systems analysis \& design } \\
\text { Head of business process development }\end{array}$ \\
\hline $\mathbf{D}$ & 20000 & 1 & $\begin{array}{l}\text { IT manager } \\
\text { CEO } \\
\text { R\&D director } \\
\text { Head of business process development }\end{array}$ \\
\hline $\mathbf{I}$ & 9700 & 3 & CIO \\
\hline $\mathbf{J}$ & 11000 & $\begin{array}{l}\text { CIO } \\
\text { Head of R\&D }\end{array}$ \\
\hline $\mathbf{K}$ & 1570 & 1 & CIO \\
\hline $\mathbf{M}$ & 1600 & 2 & Head of systems analysis \& design \\
\hline
\end{tabular}

In the second round of data collection, the researcher asked, the interviewees to share the documents related to their EA development via email. Cases A, G, I, and K shared some documents related to their EA development. In total, 8 documents (i.e., 253 pages of organizational documents) related to their EA development project were analyzed. In addition, when needed during the analysis, the interviewees were contacted to obtain more information or clarification on a statement.

\subsection{Data Analysis}

To analyze the data using the interpretivist paradigm, the researcher transcribed the interviews into text and imported them into Atlas.ti, which is a qualitative data analysis tool. Organizational documents were also analyzed using Atlas.ti. Based on the three coding principles of GTM [43], the interviews' data collected through the interviews were analyzed as they were collected. Strauss and Corbin (1998) define open coding as "the analytic process through which concepts 
and categories are identified and their properties and dimensions are discovered in data" [43]. Writing memos, labeling sentences, and comparing categories are the key activities of this phase [48]. Axial coding is "the process of relating the categories to their subcategories". In the axial coding categories link at the level of properties and dimensions [49]. In the final step of the analysis or selective coding, the central or core category is determined. The core category has relationships with most of the other categories [43]. Figure 1 presents the process of data collection and data analysis in this study.

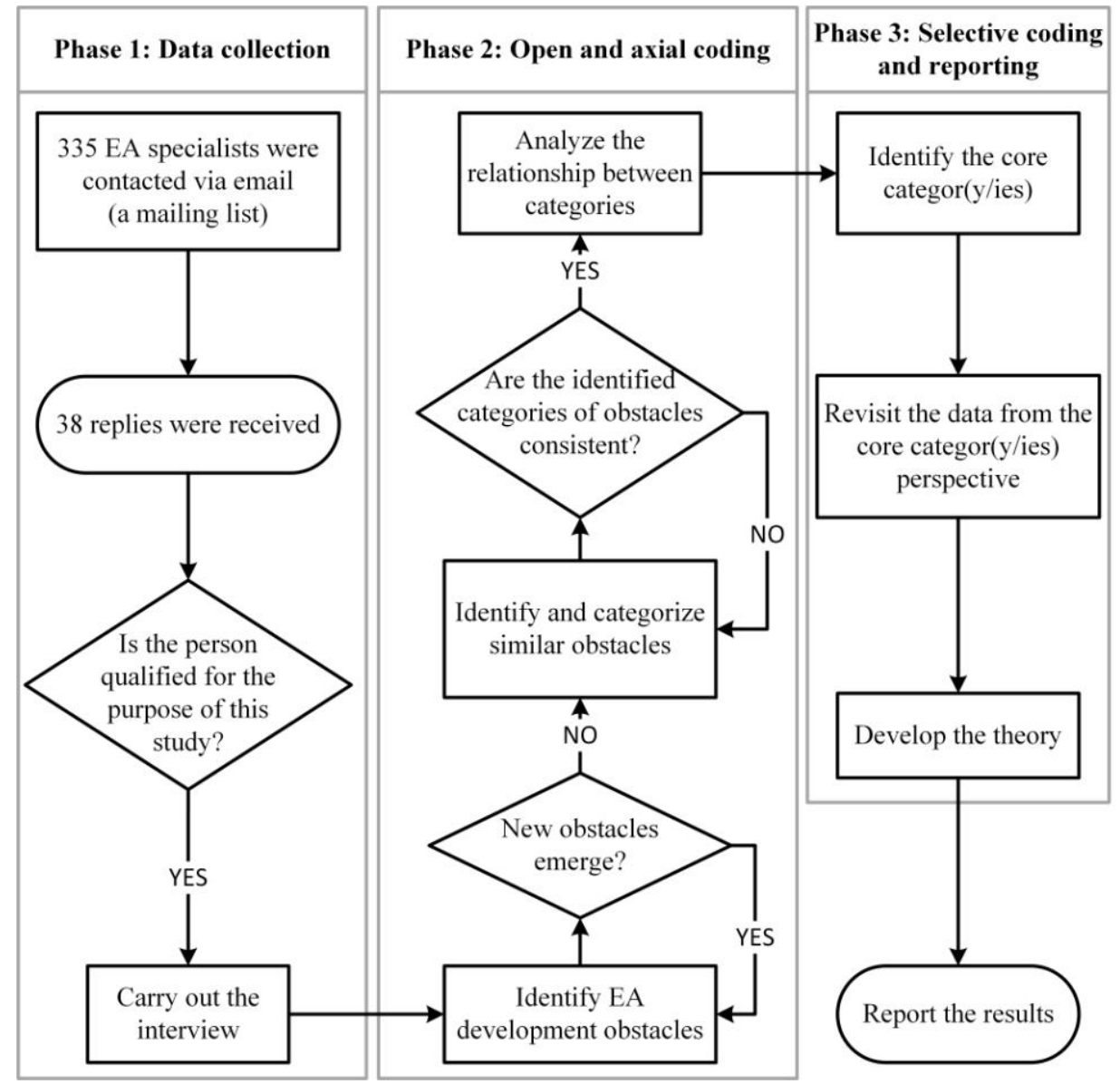

Figure 1. Research process

\subsubsection{Open Coding}

In the first phase of coding (open coding), the interviews were read and words, sentences, and paragraphs were labeled by constantly comparing the context of the interviews [43] in the Atlas.ti. 'complex environment', 'real-time data', 'need a decision maker', 'regrets' and 'low priority of EA tasks' are examples of open codes that were created. For instance, the code 'convincing manager to develop EA' was assigned to the following interview quotation: 'I remember that we were arguing about 6 months with the CEO to convince him to do the EA. There was no other option, EA had to be developed [...] we had a lot of discussions with the CEO to assure him that we could not continue doing our routine work if we wanted to reach to our goals. We needed his approval and support; that was our biggest obstacle' - Case K, CIO. Then, the conceptually similar codes were grouped to form categories and subcategories using theoretical comparison [43]. Employing theme-based interviews helped the researcher to categorize the data conceptually. During the open coding, the codes were constantly compared, similar codes were merged, and new categories emerged. 


\subsubsection{Axial Coding}

Open coding and axial coding processes were done in parallel. In axial coding relationships, such as 'is cause of', 'is associated with' and 'is part of' were identified between the categories and subcategories. For instance, it was noted that confusion in government is associated with the political issues of the government, which is associated with the change in government that has a direct impact on the management of the governmental organizations, which results in a change of management.

One of the challenges that qualitative researchers usually encounter is the recognition of the theoretical saturation point [50]. This is a milestone that should be met in a grounded theory study to prove that the data categories are well established and validated [42], [50]. [51] explain saturation as the situation "when no new categories or relevant themes are emerging" (p.148). In this study, the researcher noticed repetition in the codes after the 12th interview. The point of theoretical saturation was reached in this study as (1) no new and relevant data created any new categories; (2) the properties and dimensions of the EA obstacles were being assigned to the already established categories, and no new categories were added; and (3) the patterns in data were repeated and the relationship among categories were well established [52], [53].

\section{Investigating the EA development obstacles relationships}

At this stage, the relationships between the identified obstacles were investigated. Using Atlas.ti a network diagram was constructed to illustrate the relationships between the codes. Figure 2 shows the network diagram of all the identified EA development obstacles and their relationships.

Six types of relationships between the elements of interest in the data were identified:

1. 'Is part of' relationship when denoting that several codes, such as 'EA consultant being inefficient', 'Lack of EA consultant innovation', and 'Inexperienced EA consultant' were parts of a higher-level category named 'EA consultant-related issues'.

2. 'Is cause of' shows the one-way causality relationship between the codes. For instance, 'Change in government' is a cause of 'Change of management'.

3. 'Is associated with' indicates that two codes are associated with each other. For instance, 'Lack of management support' and 'Lack of meritocracy in hiring new employees' are associated with each other.

4. '2way causality' shows a causality relationship, which is two ways. For instance, 'personnel resistance to change' could be both cause of and caused by 'lack of communication and collaboration'.

5. 'Affects' shows when a code affects and influences another code in different ways. For instance, 'lack of EA governance' affects 'decision making about EA development'.

6. 'Hinders' is another type of relationship that shows one code can endanger another code and worsen the situation. For instance, 'old infrastructure' hinders 'internal integration' in the organization.

In this study, the EA obstacles were defined as factors that confront the EA project, decelerating progress or diminishing resources. Such problems cannot be solved easily and may potentially cause project failure. 


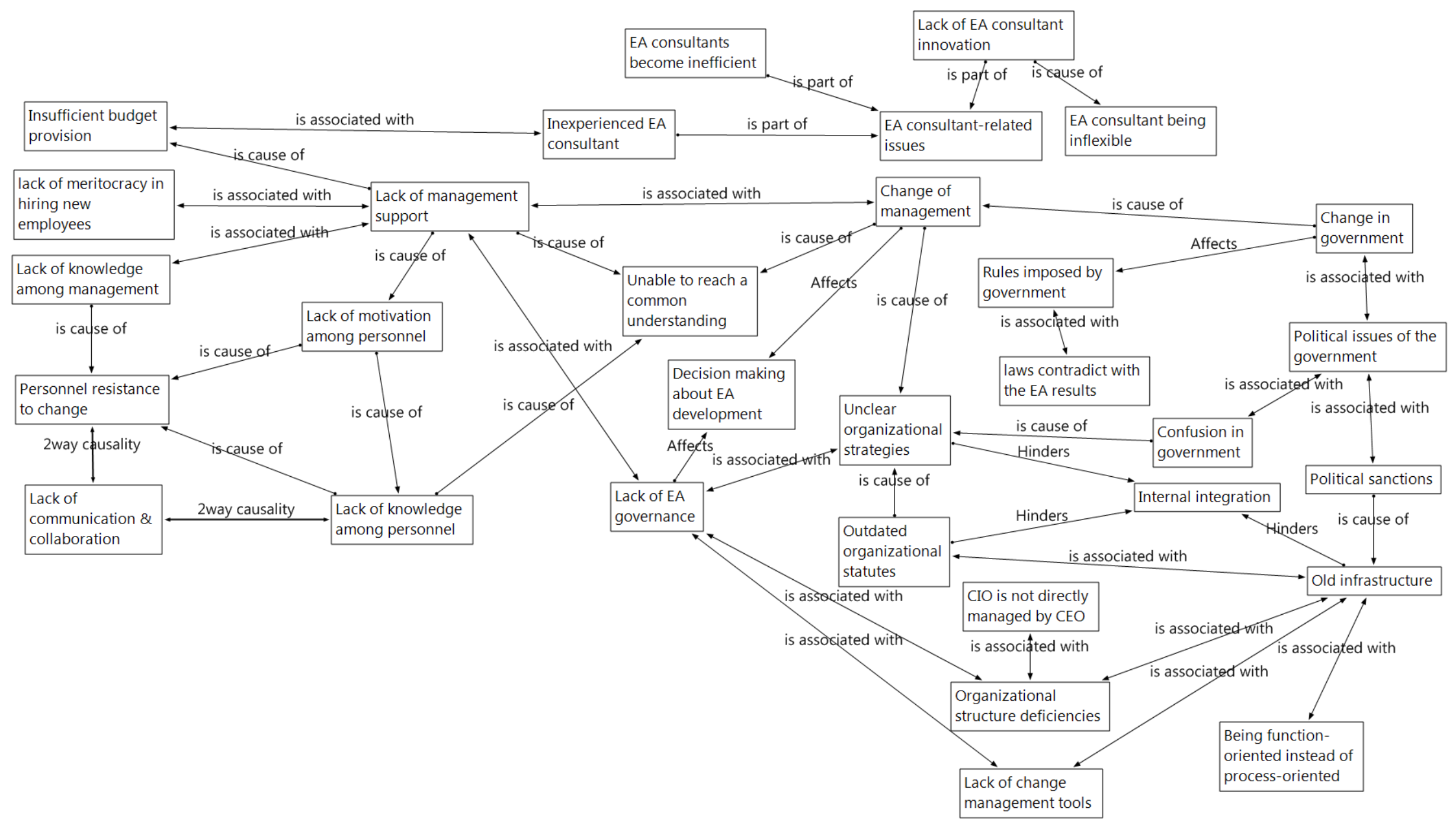

Figure 2. Network diagram of codes and their relationships 
To simplify the network diagram presented in Figure 2, the obstacles were grouped into more abstract categories. Figure 3 illustrates this categorization of the identified obstacles. Obstacles were categorized into (1) top management commitment, (2) infrastructure preparation, (3) personnel engagement, and (4) government and politics.

\begin{tabular}{|l|ll|l|l|}
\hline \multirow{2}{*}{ Personnel Engagement } & $\begin{array}{l}\text { Lack of communication and coollaboration } \\
\text { Unable to achive a common understanding } \\
\text { Lack of personnel knowledge }\end{array}$ & $\begin{array}{l}\text { Personnel change resistance } \\
\text { Lack of motivation among personnel }\end{array}$ \\
\hline \multirow{3}{*}{ Infrastructure Preparation } & $\begin{array}{l}\text { Organizational structure deficiencies } \\
\text { Outdated organizational statutes } \\
\text { Old infrastructure }\end{array}$ & $\begin{array}{c}\text { Lack of change management tools } \\
\text { Unclear organizational strategies }\end{array}$ \\
\hline \multirow{2}{*}{ Top Management Commitment } & Change of management & Lack of management knowledge & Insufficient budget provision \\
& Lack of management support & 0 \\
\hline
\end{tabular}

Figure 3. Providing a higher level of abstraction for the identified obstacles

\subsubsection{Selective Coding}

The three coding steps resulted in the identification of four main categories: top management commitment, infrastructure preparation, personnel engagement, and government and politics.

To determine the core category the obstacles were investigated to identify the precedence in addressing these obstacles (What obstacle should be addressed in priority?). The levels of priority in addressing the obstacles were determined by analyzing the relationships between the identified obstacles. In Figure 4, moving from the bottom (Top Management Commitment) to top (Personnel Engagement) the seriousness of the obstacles alleviates.

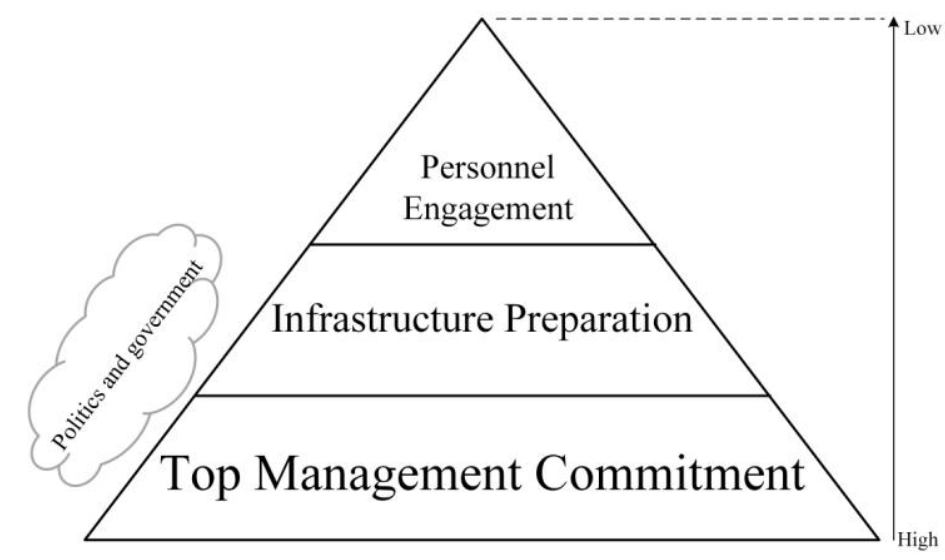

Figure 4. Levels of priority in addressing the EA development obstacles

Based on the analysis one of the most critical subjects during EA development projects is the commitment that top management level shows toward the EA project; indeed, without management's commitment, the EA project is doomed to failure. The study also reveals some factors that influence management's commitment to EA projects. For instance, when manager did not have enough EA knowledge to support the project; it was expected from the architects to provide management level with the evidence and rationale about the necessity of EA development or update for the organizations. In cases of management's support and commitment of EA projects, adequate resources and budgets were allocated to the projects. Projects, such as EA that require a lot of resources and time face with difficulties when management changes in the middle of the projects. However, the team who is responsible for EA development should be professional enough to handle the situation and help the new manager to continue with the project. Nevertheless, in some cases, a change in management ceased the EA development projects. 
After gaining top management commitment, preparing the organization's infrastructure for EA adoption is necessary. This study revealed some of the issues that need to be considered before embarking on EA development. For instance, organizational statutes should be updated, the EA team should be provided with change management tools, organizational strategies should be cleared, and organizational structure should be defined vividly. The obstacles that EA team faced in this level were more of technical and strategical type.

After achieving management commitment and preparing the organization from the technical and infrastructural aspects to initiate the EA development, it is time to address personnel related issues to ensure personnel's engagement in the EA project.

To engage personnel with the EA project, (1) EA team should enhance the communication and collaboration between project's stakeholders, (2) EA stakeholders should reach to a common understanding about EA and its influence on their jobs, (3) personnel should have enough knowledge of EA to reduce their resistance to the changes that EA will bring, and (4) the EA team and management level should motivate personnel to collaborate with the project through rewarding systems and educating them. It is necessary to be clear about the intentions and processes of EA to gain personnel's trust and improve transparency in the organization. It was realized that most of the personnel-related obstacles are rooted in the personnel's lack of knowledge.

Moreover, external obstacles, such as political issues of the government, and rules imposed by the government may hinder EA development in governmental organizations. The power that government has over the governmental organizations sometimes cause difficulties in EA projects or even their termination.

Usually, the external obstacles especially the ones imposed by the government cannot be addressed by enterprise architects, but sometimes it is possible to avoid them by adopting appropriate strategies. For instance, the EA team of the organization must know about the rules and regulations imposed by the government in order to prevent conflicts between those rules and the EA results. Furthermore, architects must be aware of the political situation of the country in order to avoid future complications. For instance, in the case of Iranian organizations, enterprise architects should be aware of the products and services, which are banned to sell to Iran due to the US sanctions over Iran.

Top management category was determined as the core category that can influence other categories. Dividing the obstacles based on these four abstract categories, the study further seeks to answer the following research question: "How does top management commitment relate to the other categories?"

\subsubsection{Relationship between Top Management Commitment and other Categories in the EA Development Projects}

Top management commitment was identified as the core category due to its fundamental influence in the EA projects from the very initial stages of the development. The emerging theory could be explained by revisiting the data from the core category perspective. It was noticed that top management commitment improves the infrastructure of the organization by allocating enough resources and budget. Furthermore, top management commitment could motivate personnel to engage with the EA development project more effectively as they see that the manager is involved and supports the EA project. In addition, it was interesting to see how the government and politics of a country can influence the EA development indirectly but significantly. Figure 5 shows the relationships between the core category (top management commitment) and other categories. 


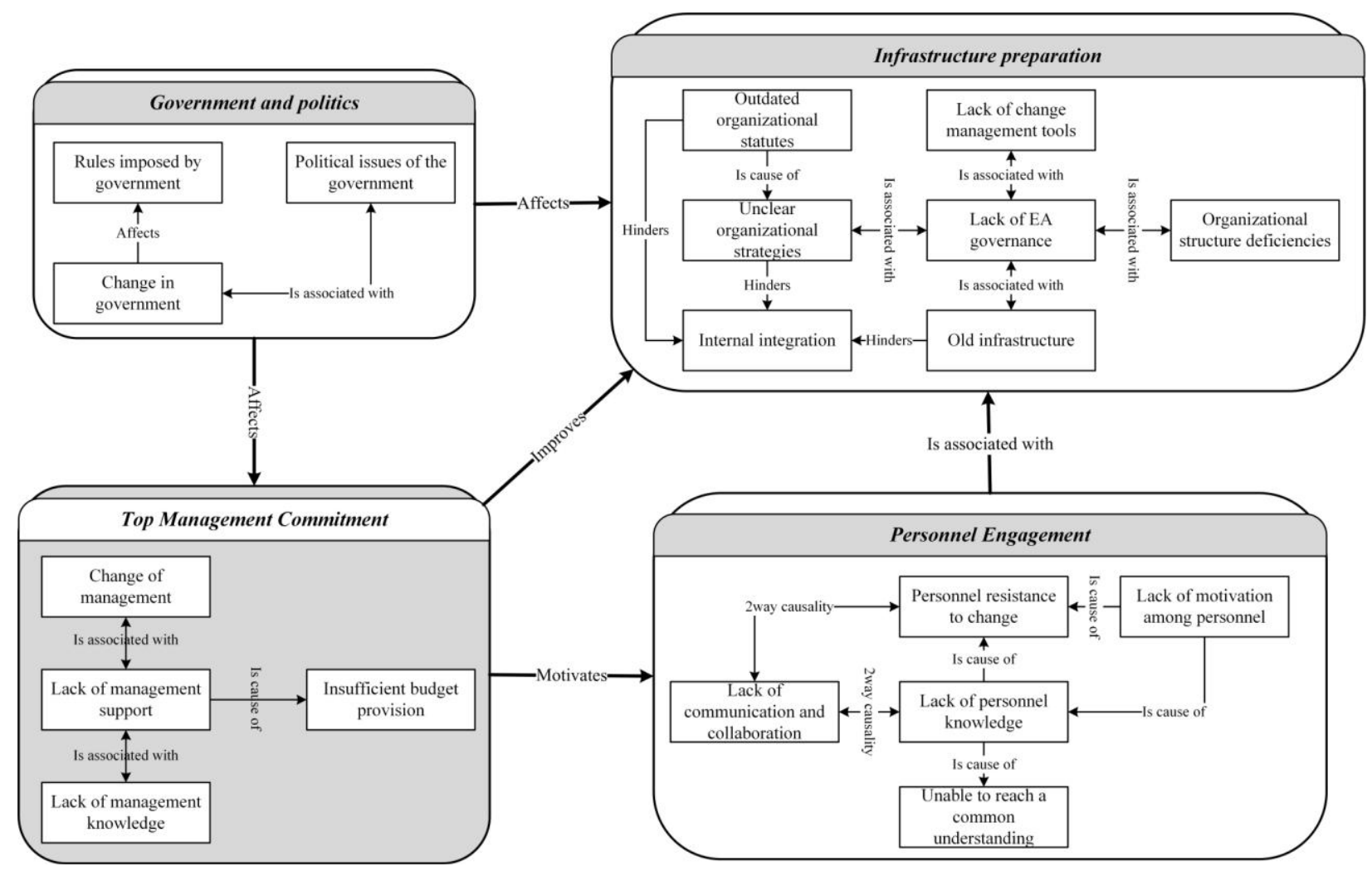

Figure 5. Investigating the relationships between the core category and other categories

\section{Findings}

17 obstacles were identified after analyzing the interviews' data collected from the governmental organizations in Iran. These obstacles are explained in this section.

\subsection{Government and Politics}

\subsubsection{Political Issues of the Government}

Confusion in government was mentioned as a common obstacle in governmental organizations. Both of the CIOs from Cases A and J mentioned that "the inappropriate definition of business in the government" and "confusion in the government regarding the long-term goals" affected their EA development in the initial stages. Also, political changes in the country were mentioned by Cases $G$ and J. They imposed difficulties for the organizations "for example when the government changes". In this situation, when the government changes, the cabinet will change, the industry minister will change. Therefore, [the organization's] boss will change. Thus, it is more likely that the project will be terminated. Further, the interviewee from Case M mentioned that because of political sanctions their company is not up to date technologically. For instance, due to the political sanctions the company that was selling SAP licenses "refused to sell them the required licenses".

\subsubsection{Rules Imposed by Government}

According to the Head of System Analysis and Design of Case G, EA development in a governmental organization is more difficult than in private organizations because of restricted rules and laws in governmental organizations. It was stated that in governmental organizations "there are managers, ministers, and a president who impose rules and restrictions on the organization". Case $J$ faced with a situation in which laws contradict the EA results. As a result of EA, they realized that sales management in one of their divisions should be removed. However, legislated laws of the county were against this EA result. 


\subsection{Personnel Engagement}

\subsubsection{Unable to Reach a Common Understanding}

The CIO of Case K stated that setting "a common desire and goal in the whole company" was their biggest obstacle. It is stated that everyone in the organization must have enough knowledge to reach a common understanding of EA. Also, the representative of Case M mentioned that everyone in the organization "must want" EA to be developed.

\subsubsection{Lack of Personnel Knowledge}

In Case J, and A lack of personnel knowledge about EA development was a challenge. The CIO of Case A stated that because of the personnel's lack of knowledge "the data gathering and interview sessions became longer than what was expected".

\subsubsection{Personnel Change Resistance}

In Cases $\mathrm{G}, \mathrm{J}$, and $\mathrm{M}$ personnel resistance to change seemed to hinder EA development greatly. The high-level management should "reassure the personnel of their job safety by communicating and involving". According to the CEO of Case $\mathrm{H}$, the reason for personnel change resistance was that the employees were "too attached to their desks and chairs". The employees thought if the processes were improved and the tasks were performed automatically, they might lose their jobs.

\subsubsection{Lack of Motivation among Personnel}

The CIOs of Cases A and K mentioned the effect of fluctuation in personnel's motivation on the EA development process. For instance, the interviewee from Case A mentioned the difficulty of coping with higher level management. Also, the CIO of Case K stated that the personnel's motivation affects the progress of EA project as "Sometimes the employee is in a good spirit and the project progresses very well but sometimes the employee is not in the mood and then even continuing the project seems so difficult".

\subsubsection{Lack of Communication and Collaboration}

In Case G, some employees felt threatened by the EA development and tried to" jeopardize" the project by giving wrong information to the EA consultant intentionally. Some of the employees wanted to "hide the truth" about their processes because "they were afraid to lose their position in the company". Additionally, the EA consultant did not have all the company's knowledge and therefore they could not verify the employees' answers regarding their processes. Consequently, the architecture became flawed and some analyses had to be redone.

\subsection{Infrastructure Preparation}

\subsubsection{Outdated Organizational Statutes}

Having old and forgotten statutes mentioned by the CIO in Case A to hinder their EA planning. The interviewee mentioned the statutes as an input for the EA development "which indicates the established goals and aims of the legislator or founder of [the organization]". However, they realized the obstacle when their EA consultant asked for these statutes and they realized that "the organizational goals and objectives were different from what the organization was doing."

\subsubsection{Old Infrastructure}

Being function-oriented instead of process-oriented mentioned by IT manager of Case D to be "the fundamental problem with most of the organizations" and it is necessary to "first fix this fundamental challenge to become process-oriented, then think about EA development." 


\subsubsection{Lack of Change Management Tools}

Lack of change management tools mentioned by the Case $M$ hindered the EA project. It was difficult for the EA team of the company to manage changes as they had not had any "monitoring tools". Each unit in the company had a person who was responsible to understand the effects of the changes in the company and they were not acting efficiently. Further, as "the environment changes rapidly and their time was limited" lack of a tool to monitor and manage changes during EA development was challenging.

\subsubsection{Unclear Organizational Strategies}

The CIO of Case A considered EA development as a total failure when the organization did not have a clear organizational strategy. In order to reach the target situation, the organization must know the "mission and vision" of the project with "a clear and up to date strategy".

In addition, Case $\mathrm{M}$ started its EA development project with "false assumptions" because the personnel did not collaborate effectively and costs increased as they had to "redo everything". Thus, the EA development took much longer than what was expected.

\subsubsection{Organizational Structure Deficiencies}

The interviewee from Case $G$ mentioned that their "biggest challenge" is that "there is not a central and powerful unit to govern [their] EA" after development. The interviewee pointed out that when the CEO does not directly manage the CIO; big IT projects like EA development, progresses slowed down and encountered more obstacles. "The manager of that department [which EA is a sub-set of] does not have enough IT knowledge or resists to changes that IT brings by proposing new technologies and the CIO's proposal might never reach to the CEO."

\subsection{Top Management Commitment}

\subsubsection{Lack of Management Support}

The CIO of Case $\mathrm{K}$ mentioned unsupportive attitude of management level as a problem in EA projects. It took more than 6 months to argue with the CEO of the company to convince him about developing EA. Getting the CEO's approval and support was their "biggest obstacle". Similarly, it was mentioned by the Case A, that "managers do not pay enough attention to EA when it is needed." Cases $\mathrm{K}$ and A stated that managers just ask for the EA results without wanting to be involved in the project. However, "Managers' supervision during the EA project motivate the personnel" as they realize that the management is also involved in the project. Further, Case M complained about the managers being unsupportive during the EA project, although they supported the project initially. Also, lack of meritocracy in hiring new and qualified personnel by the managers to be in charge of the EA project hindered EA development in Case M.

\subsubsection{Change of Management}

Constant change in management affects the policies and strategies of the organization. Changes in the organization hinder the decisions that are needed to be made for EA development. Cases $\mathbf{J}$ and $\mathrm{M}$ mentioned this obstacle. In Case $\mathrm{J}$, when the manager changed, it was not clear if the new manager "approved to continue the previous manager's works and projects." Therefore, during the development of a lengthy project like EA, it is more likely that management changes several times during the project and the changes affect the strategies and priorities of the company. In Case $\mathrm{M}$, the EA results were not accomplished, because the managers changed constantly and sometimes the projects, which are initiated as the results of EA were terminated because "the new manager did not approve the project". 


\subsubsection{Insufficient Budget Provision}

In Case G, budget provision was the biggest obstacle. The budget was too small to implement all the projects that were defined as the EA results and they were "postponed each year". A limited budget also affects the selection of the consultant. As it was mentioned by Case G, one of the important criteria in selecting a consultant was the cost.

\subsubsection{Lack of Management Knowledge}

The CIO of Case G mentioned that the managers' lack of knowledge "makes it so difficult to convince them about the usefulness of developing EA". Further, the interviewee mentioned that because of the lack of knowledge the manager did not want to be "involved" in the project.

\section{EA - Consultant Related Issues}

This issue has not been considered in our analyses because it relates only to the organizations that outsource their EA and it may not apply to every organization.

The CIO of Case $\mathbf{J}$ mentioned the Lack of professional EA consultant as one of the major obstacles. Also, the EA consultant of Case G was inexperienced with amateur members. This situation faced the EA project with difficulties as it took "much longer than expected" to finish it and "it almost failed".

According to the CIO of Case A, Lack of innovation in the consultant's team is another EA development obstacle. The interviewee mentioned that "consultant team just wants to draw a diagram and to show that they have known and modeled processes" without bringing any innovation to the job, which results in consultant being inflexible. Further, the interviewee mentioned that sometimes EA consultants become inefficient in a way that "instead of consulting they were taking orders and acted like our employees."

\section{Discussion}

A qualitative approach using grounded theory methodology was applied to study the priority in addressing the EA development obstacles. This study (1) identified the EA development obstacles in governmental organizations in Iran, (2) developed a priority structure to identify the precedence in addressing the EA development obstacles, and (3) described how top management commitment influences other EA development obstacle categories in order to facilitate EA development projects in governmental organizations.

This study shows that practitioners are constantly struggling to gain management support and commitment toward EA projects. Government and political issues affect the management's commitment in EA projects as a change in government could result in several changes in top management level of the organizations and consequently putting EA development projects in a temporary or even permanent halt. Usually, issues imposed by governments to the organizations are inevitable.

Furthermore, it was realized that personnel get motivated to collaborate with the EA project and at the same time show less resistance to the changes that EA brings when they see that top management level of the organization is supporting and are involved in the EA development project.

Top management commitment toward EA development improves the organization's infrastructure. When top management supports the EA development project, enough resources are allocated to the EA development regarding the infrastructure preparation.

This study identified 17 EA development obstacles by investigating the process of EA development in 9 governmental organizations in Iran. Moreover, comparing the findings with the literature [23]-[32], [47], [54]-[61], this research reveals five obstacles that have been neglected in the previous studies: political issues of the government, change of management, outdated organizational statutes, lack of motivation among personnel, and EA conflict with governmental laws. 
Political issues of the government: This category contains obstacles, such as confusion in government, political changes in the country, and political sanctions. Confusion in government is a challenge that many countries, regardless of being developed or developing country, might have faced for a period of time [62]-[64]. It is interesting to realize how much a government's politics influence EA development in an organization. However, none of the previous studies has mentioned this issue as an obstacle to EA development. Maybe, this situation happens more in developing countries as the interviewee from Case $\mathbf{J}$ mentioned, when the government changes the cabinet will change, the industry minister will change and consequently the strategy and the management level of the organization will be affected. Even a small change in the middle of this chain will have an impact on the organization. This emphasizes that the government's policies and organization's stability in achieving its long-term goals is required for the success of EA development in governmental organizations. Due to the peculiar political situation of Iran and studying the governmental organizations in Iran, the issue of political sanctions seems to be specific only for Iranian organizations. This obstacle appears specifically because the United States has enacted major sanctions against Iran since 1979 [65], [66]. The situation worsened in 2006 as the United Nations imposed more sanctions against Iran [67]. Iran's rank in the world regarding EA activities and e-government faced with an on-going decline since 2005. Political sanctions hinder the EA development in Iranian organizations, as they could not buy required up to date and advanced technologies and services from other countries.

Change of management: Interviewees from Cases $\mathrm{M}$ and $\mathrm{J}$, pointed out that constant change of management caused a big problem during their EA development. Change in government, which is associated with the political issues of the country causes a change in management. When the management of an organization changes, it affects the whole organization as the strategies and priorities of one manager are different from those of another manager. It was realized from the data that some managers considered EA development as a high priority task, whilst some considered it as a luxury project and completely ignored the efforts that had been done previously in the organization. In these situations, sometimes the EA development was terminated.

Outdated organizational statutes: It was mentioned by the interviewee of Case A that during EA development they realized their organizational goals and objectives mentioned in their statutes were different from what the organization was actually doing. This issue caused huge difficulties for them during EA development. Looking for the causes of this obstacle it was realized that the organization suffered from a constant change of management, and according to the political situation of the country at the time, each manager applied a different strategy compared to the previous managers. In this situation, after several changes in management, the main strategy, objective, and structure of the organization were not available for usage and they had never received an update.

Lack of motivation among personnel: This obstacle occurs especially during the postdevelopment and EA update phases when personnel is not motivated enough to update EA. In addition, it was mentioned that personnel's motivation diminished when they felt that it was hard to cope with the managers. It was suggested to employ rewarding systems to increase the personnel's motivation.

EA conflict governmental laws: As it was mentioned by the interviewee of Case J, EA development in governmental organizations is more difficult compared to private sector organizations. Rules and laws that are imposed on the organizations are more restricted in the governmental sector. Due to these restrictions imposed by the government, Case $\mathrm{J}$ faced with the situation that governmental laws contradicted with their EA results.

The studies, which have been carried out in different countries regardless of being developed or developing countries and from different industries, and both governmental and private sectors, indicate similar obstacles during EA development. Thus, the obstacles during EA development are mostly the same in different countries and over different industries. However, the government's influence on governmental organizations is probably stronger than on private 
organizations. For instance, change in government has more tangible effects on governmental organizations compared to private organizations.

\section{Conclusion}

Employing a qualitative approach and adopting grounded theory methodology, obstacles during EA development in governmental organizations in Iran were identified to provide a better understanding of the topic. 17 EA development obstacles were identified and grouped into four categories that represent a higher level of abstraction for the identified obstacles: (1) management commitment, (2) infrastructure preparation, (3) personnel engagement, and (4) government and politics.

This study determined the precedence in addressing EA development obstacles and top management commitment category was identified as the category that has the highest priority when it comes to addressing the obstacles. Based on the data analysis, top management commitment was determined as the core category that has relationships with most of the other categories of obstacles. It was realized that top management commitment motivates personnel to engage with the EA development effectively. In addition, top management commitment improves infrastructure preparation of the company by assigning adequate resources to the project. In this study, government and politics category appeared to be an influential category that affects most of the other categories directly or indirectly.

Although the issues, which are imposed by the government to the organizations, could be identified in many organizations around the world, some of the obstacles that were discussed in this study were particularly due to the political situation in Iran.

The political situation of countries might have a positive or negative effect on EA development. In the case of Iranian organizations, it usually had negative effects. It was also realized that politics and the country's relationship with the world influences the EA development, although the positive effect (no effect or supportive effects) of it may not be comprehensible until something unusual happens in the political process of a country (for example sanctions).

This study is a great help for both practitioners and researchers because of the essentials of digital capability in the success of businesses and EA being the central competence area in digital transformation. This study can assist practitioners in understanding the obstacles that they will encounter in EA development. Moreover, this study can be utilized by researchers in this field as a reference list of EA development obstacles in governmental organizations.

The data collected in this study only come from Iranian organizations and it is one of the limitations of this study. It would be interesting to conduct the same study also in other countries to confirm the generalizability of the findings of this study. Another limitation of this study is that it only investigated EA development obstacles from the management level of the organization. It would be interesting to have other EA stakeholders' perspectives as well. The mentioned limitations of this study could be considered as possible future research.

\section{Acknowledgment}

This study was funded by Academy of Finland.

\section{References}

[1] J. A. Zachman, "A Framework for Information Systems Architecture,” IBM Syst. J., vol. 26, no. 3, pp. 276-292, 1987. Available: https://doi.org/10.1147/sj.263.0276

[2] Y.-J. Lee, Y.-I. Kwon, S. Shin, and E.-J. Kim, “Advancing Government-wide Enterprise Architecture - A metamodel approach," in 2013 15th International Conference on Advanced Communication Technology (ICACT), pp. 886-892, 2013. 
[3] M. K. Haki, C. Legner, and F. Ahlemann, "Beyond EA Frameworks: towards an Understanding of the Adoption of Enterprise Architecture Management," in ECIS, p. 241, 2012.

[4] S. Roeleven and J. Broer, "Why Two Thirds of Enterprise Architecture Projects Fail," ARIS Expert Pap., 2009.

[5] C. Schmidt and P. Buxmann, "Outcomes and Success Factors of Enterprise IT Architecture Management: Empirical Insight from the International Financial Services Industry," Eur. J. Inf. Syst., vol. 20, no. 2, pp. 168-185, 2011. Available: https://doi.org/10.1057/ejis.2010.68

[6] B. Bellman and F. Rausch, "Enterprise Architecture for E-government," in Electronic government, Lecture Notes in Computer Science, vol. 3183, Springer, pp. 48-56, 2004. Available: https://doi.org/10.1007/978-3540-30078-6_9

[7] Z. Ebrahim and Z. Irani, "E-government Adoption: Architecture and barriers," Bus. Process Manag. J., vol. 11, no. 5, pp. 589-611, 2005. Available: https://doi.org/10.1108/14637150510619902

[8] L. Guijarro, "Interoperability Frameworks and Enterprise Architectures in E-government Initiatives in Europe and the United States," Gov. Inf. Q., vol. 24, no. 1, pp. 89-101, 2007. Available: https://doi.org/10.1016/j.giq.2006.05.003

[9] K. Hjort-Madsen and J. Gøtze, "Enterprise Architecture in Government-Towards a multi-level framework for managing IT in government," in 4th European Conference on e-Government, Dublin Castle, Ireland, pp. 365-374, 2004.

[10]K. Hjort-Madsen and J. Pries-Heje, "Enterprise Architecture in Government: Fad or Future?" in System Sciences, 2009. HICSS'09. 42nd Hawaii International Conference on, pp. 1-10, 2009. Available: https://doi.org/10.1109/hicss.2009.194

[11]M. Janssen and K. Hjort-Madsen, "Analyzing Enterprise Architecture In National Governments: The cases of Denmark and the Netherlands," in System Sciences, 2007. HICSS 2007. 40th Annual Hawaii International Conference on, p. 218a-218a, 2007. Available: https://doi.org/10.1109/HICSS.2007.79

[12]K. Valtonen, V. Seppanen, and M. Leppanen, "Government Enterprise Architecture Grid Adaptation in Finland," in System Sciences, 2009. HICSS'09. 42nd Hawaii International Conference on, pp. 1-10, 2009. Available:https://doi.org/10.1109/hicss.2009.232

[13]M. Alaeddini and S. Salekfard, "Investigating the Role Of An Enterprise Architecture Project in The BusinessIT Alignment in Iran," Inf. Syst. Front., vol. 15, no. 1, pp. 67-88, 2013. Available: https://doi.org/10.1007/s10796-011-9332-y

[14]N. Banaeianjahromi and K. Smolander, "What Do We Know About the Role of Enterprise Architecture in Enterprise Integration? A systematic mapping study," J. Enterp. Inf. Manag., vol. 29, no. 1, pp. 140-164, Feb. 2016. Available: https://doi.org/10.1108/JEIM-12-2014-0114

[15]M. R. Davoudi and K. Sheikhvand, "An Approach Towards Enterprise Architecture Analysis Using AHP and Fuzzy AHP," Int. J. Mach. Learn. Comput., vol. 2, no. 1, pp. 46-51, 2012. Available: https://doi.org/10.7763/IJMLC.2012.V2.88

[16]M. Jafari, P. Akhavan, and E. Nouranipour, "Developing an Architecture Model for Enterprise Knowledge: an empirical study based on the Zachman framework in Iran," Manag. Decis., vol. 47, no. 5, pp. 730-759, 2009. Available: https://doi.org/10.1108/00251740910960097

[17]M. Javanbakht, R. Rezaie, F. Shams, and M. Seyyedi, "A New Method for Decision Making And Planning In Enterprises," in Information and Communication Technologies: From Theory to Applications, 2008. ICTTA 2008. 3rd International Conference on, 2008, pp. 1-5. Available: https://doi.org/10.1109/ICTTA.2008.4529986

[18]M. R. S. Moghaddam, A. Sharifi, and E. Merati, "Using Axiomatic Design in the Process of Enterprise Architecting," in Convergence and Hybrid Information Technology, 2008. ICCIT'08. Third International Conference on, 2008, vol. 1, pp. 279-284. Available: https://doi.org/10.1109/ICCIT.2008.272

[19]B. Zarei and A. Ghapanchi, "Guidelines for Government-To-Government Initiative Architecture in Developing Countries," Int. J. Inf. Manag., vol. 28, no. 4, pp. 277-284, Aug. 2008. Available: https://doi.org/10.1016/j.ijinfomgt.2008.02.008

[20]NEAC, "Important Achievements of More Than A Decade on Enterprise Architecture in Iran," National Enterprise Architecture Committee, 2015. [Online]. Available: http://www.neac.ir/index.php. [Accessed: 14Dec-2015].

[21]J. Schekkerman, “Trends in Enterprise Architecture 2005: How are organizations progressing," Inst. Enterp. Archit. Dev. Amersfoort, 2005. 
[22] United Nations, “United Nations E-Governmnet Survey 2014, E-Government for the Future We Want,” 2014.

[23]R. Bricknall, G. Darrell, H. Nilsson, and K. Pessi, "Enterprise Architecture: critical factors affecting modelling and management," in ECIS, pp. 2349-2361, 2006.

[24]K. Hjort-Madsen, "Enterprise Architecture Implementation and Management: A case study on interoperability," in System Sciences, 2006. HICSS'06. Proceedings of the 39th Annual Hawaii International Conference on, vol. 4, p. 71c-71c, 2006. Available: https://doi.org/10.1109/HICSS.2006.154

[25]H. Isomäki and K. Liimatainen, "Challenges of Government Enterprise Architecture Work-Stakeholders' Views," in Electronic Government, Springer, pp. 364-374, $2008 . \quad$ Available: https://doi.org/10.1007/978-3-540-85204-9_31

[26] S. H. Kaisler, F. Armour, and M. Valivullah, "Enterprise Architecting: Critical problems," in System Sciences, 2005. HICSS'05. Proceedings of the 38th Annual Hawaii International Conference on, p. 224b-224b, 2005. Available: https://doi.org/10.1109/HICSS.2005.241

[27] V. Seppänen, J. Heikkilä, and K. Liimatainen, "Key Issues In EA-Implementation: case study of two Finnish government agencies," in Commerce and Enterprise Computing, 2009. CEC'09. IEEE Conference on, pp. 114-120, 2009. Available: https://doi.org/10.1109/CEC.2009.70

[28]K. Winter, S. Buckl, F. Matthes, and C. M. Schweda, "Investigating the State-of-the-Art in Enterprise Architecture Management Methods in literature and Practice," MCIS Proceedings, p. 90, 2010.

[29]M.-M. Saarelainen and V. Hotti, "Does Enterprise Architecture Form the Ground for Group Decisions in eGovernment Programme? Qualitative Study of the Finnish National Project for IT in Social Services," in Enterprise Distributed Object Computing Conference Workshops (EDOCW), 2011 15th IEEE International, pp. 11-17, 2011. Available: https://doi.org/10.1109/edocw.2011.26

[30]K. Valtonen, S. Mäntynen, M. Leppänen, and M. Pulkkinen, "Enterprise Architecture Descriptions for Enhancing Local Government Transformation and Coherency Management: Case Study," in Enterprise Distributed Object Computing Conference Workshops (EDOCW), 2011 15th IEEE International, pp. 360-369, 2011. Available: https://doi.org/10.1109/edocw.2011.39

[31]C.-H. Chuang and J. van Loggerenberg, "Challenges Facing Enterprise Architects: A South African Perspective," in 2010 43rd Hawaii International Conference on System Sciences (HICSS), pp. 1-10, 2010. Available: https://doi.org/10.1109/HICSS.2010.449

[32] N. Banaeianjahromi, "Where Enterprise Architecture Development Fails a Multiple Case Study Of Governmental Organizations," in 2018 12th International Conference on Research Challenges in Information Science (RCIS), pp. 1-9, 2018. Available: https://doi.org/10.1109/RCIS.2018.8406644

[33] J. Lapalme, A. Gerber, A. Van der Merwe, J. Zachman, M. De Vries, and K. Hinkelmann, "Exploring the Future of Enterprise Architecture: A Zachman perspective," Comput. Ind., vol. 79, pp. 103-113, 2016. Available: https://doi.org/10.1016/j.compind.2015.06.010

[34]K. D. Niemann, From Enterprise Architecture to IT Governance, Springer, 2006. Available: https://doi.org/10.1007/978-3-8348-9011-5

[35] J. W. Ross, P. Weill, and D. C. Robertson, Enterprise Architecture as Strategy: Creating a foundation for business execution. Harvard Business Press, 2006

[36] D. Simon, K. Fischbach, and D. Schoder, "Enterprise architecture Management and Its Role in Corporate Strategic Management," Inf. Syst. E-Bus. Manag., vol. 12, no. 1, pp. 5-42, Feb. 2014. Available: https://doi.org/10.1007/s10257-013-0213-4

[37] R. Winter and R. Fischer, "Essential layers, Artifacts, And Dependencies of Enterprise Architecture," in Enterprise Distributed Object Computing Conference Workshops, 2006. EDOCW'06. 10th IEEE International, 2006, pp. 30-30. Available: https://doi.org/10.1109/edocw.2006.33

[38] N. Banaeianjahromi and K. Smolander, "Understanding Obstacles in Enterprise Architecture Development," in ECIS 2016, 2016.

[39] M. Rohloff, "Enterprise Architecture-Framework and Methodology for the Design of Architectures in the Large," ECIS 2005 Proc., p. 113, 2005.

[40] N. Banaeianjahromi, "On the Role of Enterprise Architecture in Enterprise Integration," Acta Univ. Lappeenrantaensis, 2018.

[41] B. G. Glaser and A. L. Strauss, The Discovery of Grounded Theory: Strategies for qualitative research. Transaction Publishers, 1967. 
[42] J. M. Corbin and A. Strauss, "Grounded Theory Research: Procedures, canons, and evaluative criteria," Qual. Sociol., vol. 13, no. 1, pp. 3-21, 1990. Available: https://doi.org/10.1007/BF00988593

[43] A. Strauss and J. Corbin, The Basics of Qualitative Research: Techniques and Procedures for Developing Grounded Theory, 1st Edition. Sage, London, 1998.

[44] G. Goldkuhl and S. Cronholm, "Adding Theoretical Grounding to Grounded Theory: Toward Multi-Grounded Theory," Int. J. Qual. Methods, vol. 9, no. 2, pp. 187-205, Jun. 2010. Available: https://doi.org/10.1177/160940691000900205

[45] G. McGhee, G. R. Marland, and J. Atkinson, "Grounded Theory Research: literature reviewing and reflexivity," J. Adv. Nurs., vol. 60, no. 3, pp. 334-342, Nov. 2007. Available: https://doi.org/10.1111/j.1365-2648.2007.04436.x

[46] M. Q. Patton, Qualitative research. Wiley Online Library, 2005.

[47] M. Lange and J. Mendling, “An Experts' Perspective on Enterprise Architecture Goals, Framework Adoption and Benefit Assessment," in Enterprise Distributed Object Computing Conference Workshops (EDOCW), 2011 15th IEEE International, pp. 304-313, 2011. Available: https://doi.org/10.1109/edocw.2011.41

[48] K. Locke, Grounded Theory in Management Research. Sage, 2001.

[49] A. Strauss and J. Corbin, Basics of Qualitative Research: Grounded Theory Procedures and Techniques. Sage Publications, 1990.

[50] G. A. Bowen, "Naturalistic Inquiry and the Saturation Concept: a research note," Qual. Res., vol. 8, no. 1, pp. 137-152, Feb. 2008. Available: https://doi.org/10.1177/1468794107085301

[51] J. Corbin and A. Strauss, Basics of Qualitative Research: Techniques and Procedures for Developing Grounded Theory, 3rd Edition. London: Sage, 2008. Available: https://doi.org/10.4135/9781452230153

[52] J. E. B. Duchscher and D. Morgan, "Grounded Theory: reflections on the emergence vs. forcing debate," J. Adv. Nurs., vol. 48, no. 6, pp. 605-612, Dec. 2004. Available: https://doi.org/10.1111/j.1365-2648.2004.03249.x

[53] J. M. Morse, “The Significance of Saturation,” Qual. Health Res., vol. 5, no. 2, pp. 147-149, 1995. Available: https://doi.org/10.1177/104973239500500201

[54] T. Iyamu, "The factors Affecting Institutionalisation of Enterprise Architecture in the Organisation," in Commerce and Enterprise Computing, 2009. CEC'09. IEEE Conference on, pp. 221-225, 2009. Available: https://doi.org/10.1109/CEC.2009.57

[55] B. Jahani, S. Reza Seyyed Javadein, and H. Abedi Jafari, "Measurement of Enterprise Architecture Readiness within Organizations," Bus. Strategy Ser., vol. 11, no. 3, pp. 177-191, 2010. Available: https://doi.org/10.1108/17515631011043840

[56] A. Nakakawa, P. van Bommel, and H. A. Proper, "Challenges of Involving Stakeholders When Creating Enterprise Architecture," in 5th SIKS/BENAIS Conference on Enterprise Information Systems, pp. 43-55, 2010.

[57] C. Lucke and U. Lechner, "Goal-Oriented Requirements Modeling as a Means to Address Stakeholder-Related Issues in EA.," in Wirtschaftsinformatik, p. 43, 2011.

[58] S. Roth, M. Hauder, M. Farwick, R. Breu, and F. Matthes, "Enterprise Architecture Documentation: Current Practices and Future Directions.," in Wirtschaftsinformatik, p. 58, 2013.

[59] M. Hauder, S. Roth, C. Schulz, and F. Matthes, "An Examination Of Organizational Factors Influencing Enterprise Architecture Management Challenges.," in ECIS, p. 175, 2013.

[60] F. Nikpay, H. Selamat, B. D. Rouhani, and P. Nikfard, "A Review of Critical Success Factors of Enterprise Architecture Implementation," in Informatics and Creative Multimedia (ICICM), 2013 International Conference on, pp. 38-42, 2013. Available: https://doi.org/10.1109/ICICM.2013.16

[61] H. Wan, A. Luo, and X. Luo, "How Enterprise Architecture Formative Critical Success Facets Might Affect Enterprise Architecture Success: A Literature Analysis," in Service Science and Knowledge Innovation, Springer, pp. 197-209, 2014. Available: https://doi.org/10.1007/978-3-642-55355-4_20

[62] M. N. Cooper, The Transformation of Egypt (RLE Egypt). Routledge, 2013. Available: https://doi.org/10.4324/9780203070345

[63] T. Mc Namara et al., "Review of Developments, Structure and Management in the Public Sector 2007," Adm.DUBLIN, vol. 55, no. 4, p. 1, 2008. 
[64] W. H. Veazie and T. F. Connolly, "The Marketing of Information Analysis Center Products and Services," Jun. 1971.

[65] S. Fayazmanesh, "The Politics of the US Economic Sanctions against Iran," Rev. Radic. Polit. Econ., vol. 35, no. 3, pp. 221-240, 2003. Available: https://doi.org/10.1177/0486613403254535

[66] K. Katzman, “The Iran Sanctions Act (ISA),” 2009.

[67] United Nations, "Security Council Imposes Sanctions on Iran for Failure to Halt Uranium Enrichment, Unanimously Adopting Resolution 1737 (2006) | Meetings Coverage and Press Releases," United Nations, 2006. [Online]. Available: http://www.un.org/press/en/2006/sc8928.doc.htm. [Accessed: 23-Dec-2015]. 